\title{
A Molecular Cage-Based [2]Rotaxane That Behaves as a Molecular Muscle
}

\author{
Chun-Ju Chuang, ${ }^{\dagger}$ Wan-Sheung Li, ${ }^{\ddagger}$ Chien-Chen Lai, ${ }^{\S}$ Yi-Hung Liu, ${ }^{\dagger}$ \\ Shie-Ming Peng, ${ }^{\dagger}$ Ito Chao, ${ }^{*, \neq}$ and Sheng-Hsien Chiu ${ }^{*, \dagger}$
}

\begin{abstract}
Department of Chemistry, National Taiwan University, No. 1, Sec. 4, Roosevelt Road, Taipei, Taiwan 10617, R.O.C., Institute of Chemistry, Academia Sinica, Nankang, Taiwan, R.O.C., and Institute of Molecular Biology, National Chung Hsing University and Department of Medical Genetics, China Medical University Hospital,
\end{abstract}

Taichung, Taiwan, R.O.C.

shchiu@ntu.edu.tw;ichao@chem.sinica.edu.tw

Received November 17, 2008

\section{ABSTRACT}
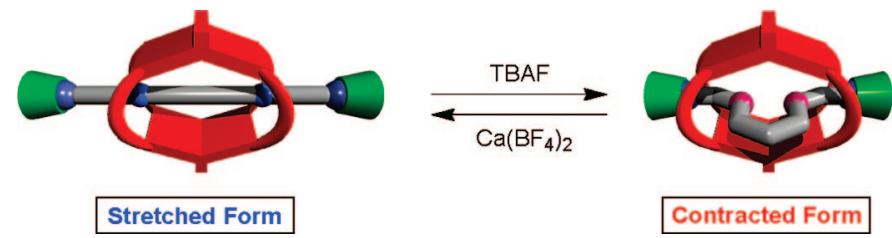

We report a molecular cage-based [2]rotaxane that functions as an artificial molecular muscle through the control of the addition and removal of fluoride anions. The percentage change in molecular length of the [2]rotaxane is about $36 \%$ between the stretched and contracted states, which is larger than the percentage change ( 27\%) in human muscle.

Skeletal muscles are responsible for the motion of many biological systems. On the molecular scale, these muscles are delicately controlled linear machines ${ }^{1}$ exhibiting reversible, programmed contraction and stretching movements. To mimic the unique function of biological muscles, several

\footnotetext{
National Taiwan University.

$¥$ Academia Sinica.

Institute of Molecular Biology.

(1) For reviews, see: (a) Balzani, V.; Credi, A.; Raymo, F. M.; Stoddart, J. F. Angew. Chem., Int. Ed. 2000, 39, 3348-3391. (b) Kay, E. R.; Leigh, D. A.; Zerbetto, F. Angew. Chem., Int. Ed. 2007, 46, 72-191. (c) Champin, B.; Mobian, P.; Sauvage, J.-P. Chem. Soc. Rev. 2007, 36, 358-366.

(2) (a) Jiménez-Molero, M. C.; Dietrich-Buchecker, C.; Sauvage, J.-P Angew. Chem., Int. Ed. 2000, 39, 3284-3287. (b) Collin, J.-P.; DietrichBuchecker, C.; Gavinã, P.; Jiménez-Molero, M. C.; Sauvage, J.-P. Acc. Chem. Res. 2001, 34, 477-487. (c) Marsella, M. J.; Piao, G.; Tham, F. S. Synthesis 2002, 1133-1135. (d) Jiménez-Molero, M. C.; Dietrich-Buchecker, C.; Sauvage, J.-P. Chem. Commun. 2003, 1613-1616. (e) Tseng, H.-R.; Vignon, S. A.; Stoddart, J. F. Polym. Prepr. (Am. Chem. Soc. Div. Polym. Chem.) 2003, 44, 377-378. (f) Liu, Y.; Flood, A. H.; Bonvallet, P. A.; Vignon, S. A.; Northrop, B. H.; Tseng, H.-R.; Jeppesen, J. O.; Huang, T. J.; Brough, B.; Baller, M.; Magonov, S.; Solares, S. D.; Goddard, W. A.; Ho, C.-H.; Stoddart, J. F. J. Am. Chem. Soc. 2005, 127, 9745-9759. (g) Coutrot, F.; Romuald, C.; Busseron, E. Org. Lett. 2008, 10, 3741-3744. (h) Wu, J.; Leung, K. C.-F.; Benítez, D.; Han, J.-Y.; Cantrill, S. J.; Fang, L.; Stoddart, J. F. Angew. Chem., Int. Ed. 2008, 47, 7470-7474. (i) Dawson, R. E.; Lincoln, S. F.; Easton, C. J. Chem. Commun. 2008, 3980-3982.
}

groups are developing artificial linear molecular assemblies that undergo controllable stretching and contraction. ${ }^{2}$ The design of these interlocked molecular muscles is elegant: two interlocked components of hermaphroditic rotaxane-like systems move with respect to one another upon the sequential application and removal of a stimulus, thereby changing the distance between the two termini in a controllable manner (Figure 1). ${ }^{3}$ Staying with the concept of rotaxane-based systems, we envisioned an alternative type of molecular muscle: one in which the thread-like component can exist in both extended and folded conformations within its encircling container-like macrocycle; muscle-like molecular motion would ensue if different recognition sites on the

(3) For doubly threaded hermaphroditic systems known as [c2]daisy chains, see: (a) Hoshino, T.; Miyauchi, M.; Kawaguchi, Y.; Yamaguchi, H.; Harada, A. J. Am. Chem. Soc. 2000, 122, 9876-9877. (b) Fujimoto, T.; Sakata, Y.; Kaneda, T. Chem. Commun. 2000, 2143-2144. (c) Cantrill, S. J.; Youn, G. J.; Stoddart, J. F.; Williams, D. J. J. Org. Chem. 2001, 66, 68576872. (d) Onagi, H.; Easton, C. J.; Lincoln, S. F. Org. Lett. 2001, 3, 10411044. (e) Chiu, S.-H.; Rowan, S. J.; Cantrill, S. J.; Stoddart, J. F.; White, A. J. P.; Williams, D. J. Chem. Commun. 2002, 2848-2849. (f) Guidry, E. N.; Li, J.; Stoddart, J. F.; Grubbs, R. H. J. Am. Chem. Soc. 2007, 129, 8944-8945. (g) Ueng, S.-H.; Hsueh, S.-Y.; Lai, C.-C.; Liu, Y.-H.; Peng, S.-M.; Chiu, S.-H. Chem. Commun. 2008, 817-819. 


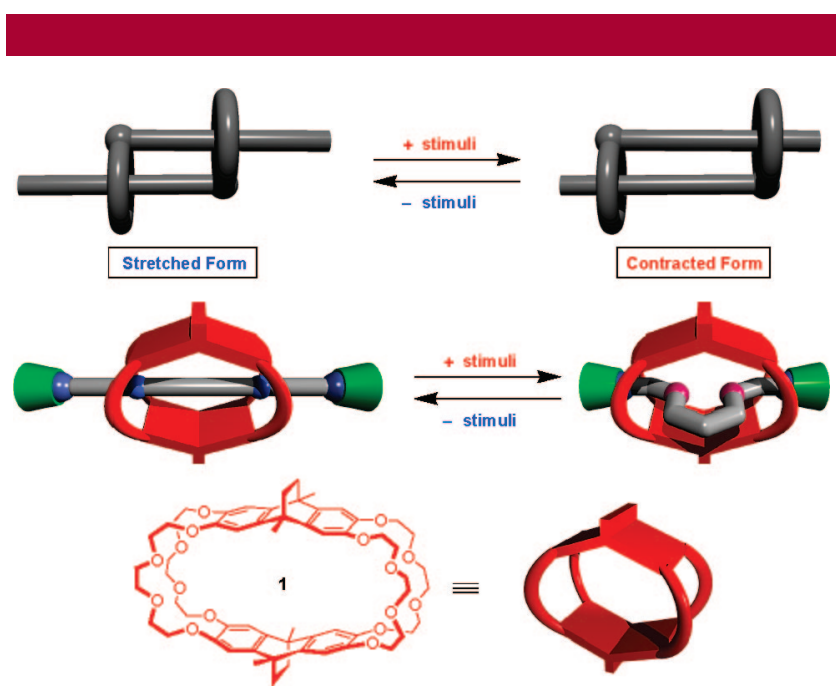

Figure 1. Cartoon representation of the operation of the molecular muscles based on doubly threaded and molecular cage-based systems.

thread-like component interacted with the macrocyclic component under orthogonal conditions. Previously, we reported that the molecular cage $\mathbf{1}$ forms two types of [2]pseudorotaxane-like complexes, i.e., where complementary guest species are threaded through its two types of macrocyclic cavities. ${ }^{4}$ Herein, we report a [2] rotaxane, which incorporates this molecular cage, that functions as an artificial molecular muscle that can be controlled through the addition and removal of fluoride ions.

To mimic the function of biological muscle, [2]rotaxane 2- $\mathrm{H}_{2} \cdot 4 \mathrm{PF}_{6}$, which contains two $\mathrm{NH}_{2}{ }^{+}$and pyridinium units in the thread component linked by flexible $n$-alkyl chains, was designed. We anticipated that by controlling which of the recognition sites $\left(\mathrm{NH}_{2}{ }^{+}\right.$or pyridinium stations) of the dumbbell-shaped component interacted with the DB24C8like openings of the molecular cage component, we would obtain both stretched and contracted conformations of the [2]rotaxane, such that the distance between the termini of the thread-like component would vary substantially, thereby mimicking muscle-like behavior.

We synthesized the thread-like trication $3-\mathrm{H}_{2} \cdot 3 \mathrm{PF}_{6}$ from ditosylated 1,8-octanediamine ${ }^{5}$ in three steps (see Supporting Information). An equimolar ( $2 \mathrm{mM})$ mixture of the molecular cage 1 and $3-\mathrm{H}_{2} \cdot 3 \mathrm{PF}_{6}$ in $\mathrm{CD}_{3} \mathrm{CN}$ at room temperature provided a complicated ${ }^{1} \mathrm{H}$ NMR spectrum that implied the presence of more than one type of complex, with corresponding rates of association and/or dissociation slower than the NMR spectroscopic time scale under these conditions (Figure 2a). Heating this solution at $323 \mathrm{~K}$ for $4 \mathrm{~h}$ gave a single

(4) Lin, C.-F.; Liu, Y.-H.; Lai, C.-C.; Peng, S.-M.; Chiu, S.-H. Angew. Chem., Int. Ed. 2006, 45, 3176-3181.

(5) (a) Iwata, M.; Kuzuhara, H. Bull. Chem. Soc. Jpn. 1982, 55, $2153-$ 2157. (b) Iwata, M.; Kuzuhara, H. J. Org. Chem. 1983, 48, 1282-1286.

(6) Chen, N.-C.; Lai, C.-C.; Liu, Y.-H.; Peng, S.-M.; Chiu, S.-H. Chem. Eur. J. 2008, 14, 2904-2908.

(7) Crystallographic data (excluding structure factors) for rotaxane 2- $\mathrm{H}_{2} \cdot 4 \mathrm{PF}_{6}$ has been deposited with the Cambridge Crystallographic Data Centre as supplementary publication no. CCDC-702214. Copies of the data can be obtained free of charge upon application to CCDC, 12 Union Road, Cambridge CB21EZ, UK [fax: (+44) 1223-336-033; e-mail: deposit@ccdc.cam.ac.uk].

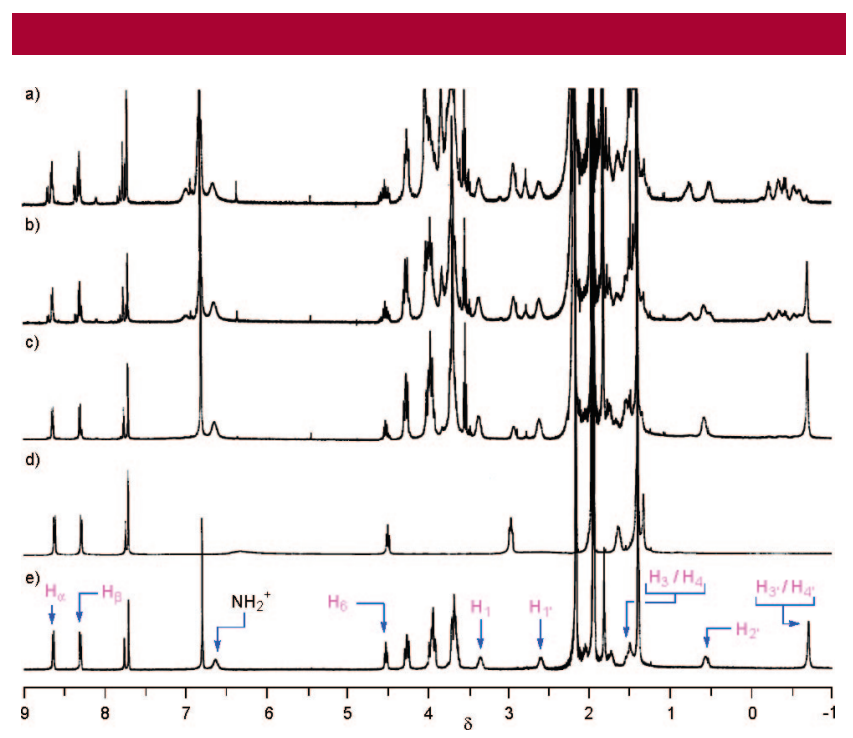

Figure 2. Partial ${ }^{1} \mathrm{H}$ NMR spectra $\left(400 \mathrm{MHz}, \mathrm{CD}_{3} \mathrm{CN}, 298 \mathrm{~K}\right)$ of (a) an equimolar mixture of $\mathbf{1}$ and $3-\mathrm{H}_{2} \cdot 3 \mathrm{PF}_{6}(2 \mathrm{mM})$; (b) the mixture in (a) heated at $323 \mathrm{~K}$ for $1 \mathrm{~h}$; (c) the mixture in (a) heated at $323 \mathrm{~K}$ for $4 \mathrm{~h}$; (d) $4-\mathrm{H}_{2} \cdot 4 \mathrm{PF}_{6}$; and (e) the [2]rotaxane $2-\mathrm{H}_{2} \cdot 4 \mathrm{PF}_{6}$.

set of signals for the complex in the ${ }^{1} \mathrm{H}$ NMR spectrum (Figure $2 \mathrm{c}$ ); the shifts in the positions of the signals of the pyridinium protons and their neighboring are minor compared with the dramatic shifts in the signals of the $n$-octyl unit's protons, relative to those in the spectrum of the dumbbell $4-\mathrm{H}_{2} \cdot 4 \mathrm{PF}_{6}$ (Figure 2d), suggesting that the structure of this complex in solution was most likely the semirotaxane $\left(\mathbf{1} \supset \mathbf{3}-\mathrm{H}_{2}\right) \cdot 3 \mathrm{PF}_{6}$. After adding 4-(3,5-di-tert-butylphenyl)pyridine $\mathbf{5}^{6}(200 \mathrm{mM})$ to a solution of the semirotaxane $\left(1 \supset 3-\mathrm{H}_{2}\right) \cdot 3 \mathrm{PF}_{6}$, prepared by heating a $\mathrm{CH}_{3} \mathrm{CN}$ solution of the molecular cage $1(50 \mathrm{mM})$ and the thread-like tricationic salt $3-\mathrm{H}_{2} \cdot 3 \mathrm{PF}_{6}(60 \mathrm{mM})$ for $4 \mathrm{~h}$ at 323 $\mathrm{K}$, the solution mixture was stirred for 6 days, and the desired [2] rotaxane $2-\mathrm{H}_{2} \cdot 4 \mathrm{PF}_{6}$ was obtained in $30 \%$ yield after ion exchange and column chromatography (Scheme 1).

2D COSY and NOSY experiments helped us to identify most of the signals in the ${ }^{1} \mathrm{H}$ NMR spectrum of the [2]rotaxane $2-\mathrm{H}_{2} \cdot 4 \mathrm{PF}_{6}$ in $\mathrm{CD}_{3} \mathrm{CN}$ at $298 \mathrm{~K}$ (see Supporting Information). The significant upfield shifts of the signals for the methylene units of the central $n$-octyl chain relative to those of the $n$-hexyl protons linking the ammonium and pyridinium stations - in addition to the negligible shifts in the signals of the protons of the pyridinium units compared with those of the dumbbell $4-\mathrm{H}_{2} \cdot 2 \mathrm{PF}_{6}-$ suggested that, under these conditions, the molecular cage interacted noncovalently with the two $\mathrm{NH}_{2}{ }^{+}$stations. Thus, the "stretched" form of the [2] rotaxane $2-\mathrm{H}_{2} \cdot 4 \mathrm{PF}_{6}$ predominated in solution under these conditions.

We grew single crystals suitable for X-ray crystallography through liquid diffusion of isopropyl ether into a solution mixture of $\mathrm{CH}_{3} \mathrm{CN}$ and $\mathrm{MeOH}(1: 1)$ of $2-\mathrm{H}_{2} \cdot 4 \mathrm{PF}_{6}$. The solidstate structure ${ }^{7,8}$ (Figure 3 ) reveals the expected [2]rotaxane

(8) Crystal data for $2-\mathrm{H}_{2} \cdot 4 \mathrm{PF}_{6}:\left[\mathrm{C}_{118} \mathrm{H}_{170} \mathrm{O}_{16} \mathrm{~N}_{4} \cdot 4 \mathrm{CH}_{3} \mathrm{CN} \cdot 2 \mathrm{CH}_{3} \mathrm{OH}\right]\left[4 \mathrm{PF}_{6}\right]$, $M_{\mathrm{r}}=2708.76$, monoclinic, space group $p 2{ }_{1} / c, a=20.6795$ (12), $b=$ 21.8470 (8), $c=15.2230$ (7) A, $V=6745.0(6) \AA^{3}, \rho_{\text {calcd }}=1.334 \mathrm{~g} \mathrm{~cm}^{-3}$, $\mu(\mathrm{Mo} \mathrm{K} \alpha)=1.363 \mathrm{~mm}^{-1}, T=150(2) \mathrm{K}$, yellow cubes; 18,446 independent measured reflections, $F^{2}$ refinement, $R_{1}=0.0623, w R_{2}=0.1607$. 
Scheme 1. Synthesis of a [2]Rotaxane That Functions As a Molecular Muscle Cage-Based System
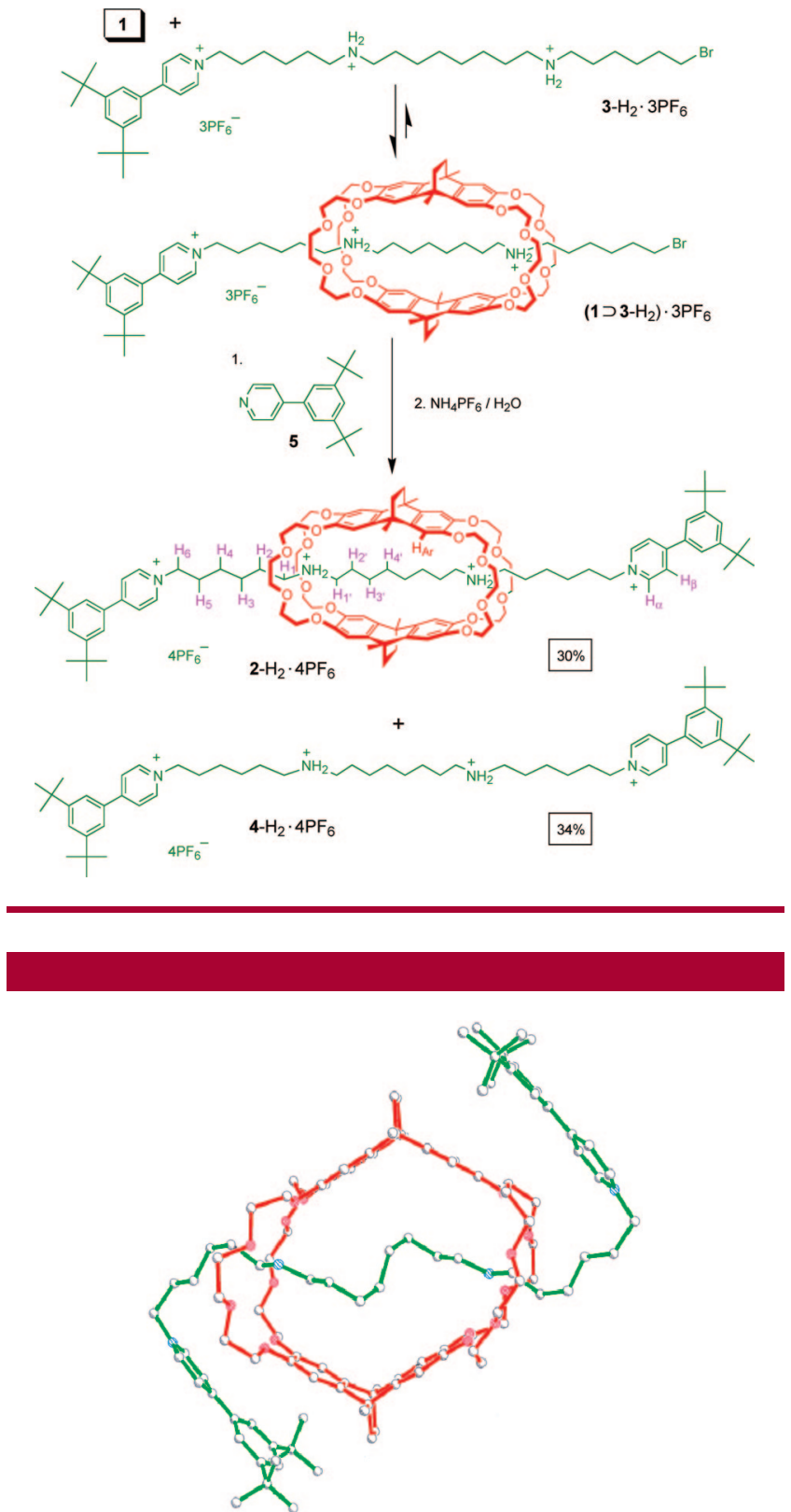

Figure 3. Ball-and-stick representation of the solid state structure of the [2]rotaxane $2-\mathrm{H}_{2}{ }^{4+}$. Atom labels: $\mathrm{C}$, gray; $\mathrm{H}$, pink; $\mathrm{O}$, orange; $\mathrm{N}$, blue.

molecular geometry: the dumbbell-shaped component is threaded through the two 24-membered-ring openings of the molecular cage unit, and the two $\mathrm{NH}_{2}{ }^{+}$centers are located within the crown ether-like cavities.

Initially, we attempted to contract the [2] rotaxane $2-\mathrm{H}_{2} \cdot 4 \mathrm{PF}_{6}$ through the addition of bases. We found, however, no conclusive ${ }^{1} \mathrm{H}$ NMR spectroscopic evidence for contraction when we added 10 equiv of triethylamine $\left(\mathrm{Et}_{3} \mathrm{~N}\right), 1,8$ diaminonaphthalene (proton sponge), or potassium tertbutoxide to a $\mathrm{CD}_{3} \mathrm{CN}$ solution of the [2] rotaxane $2-\mathrm{H}_{2} \cdot 4 \mathrm{PF}_{6}$ (see Supporting Information).
We suspect that responsibility for this behavior lies in (i) the two less-acidic complexed $\mathrm{NH}_{2}{ }^{+}$centers in the [2]rotaxane $^{9}$ and (ii) an insufficient gain in stability, through new ion-dipole and $[\mathrm{C}-\mathrm{H} \cdots \mathrm{O}]$ hydrogen bonding interactions between the pyridinium and DB24C8-like units, to compensate for the loss of $\left[\mathrm{N}^{+}-\mathrm{H} \cdots \mathrm{O}\right]$ hydrogen bonds.

Because the interactions between secondary dialkylammonium ions and crown ethers are affected by the nature of the counteranions, ${ }^{10}$ we turned our attention to controlling the muscle-like behavior of the [2] rotaxane $2-\mathrm{H}_{2} \cdot 4 \mathrm{PF}_{6}$ through anion exchange (Figure 4). After adding 2 equiv of

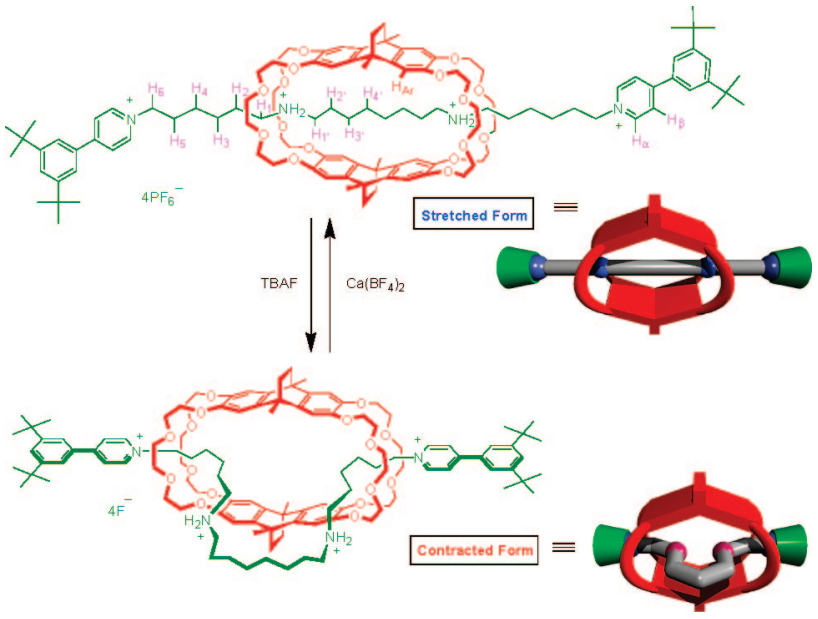

Figure 4. Mimicking the operation of a muscle using the molecular cage-based [2]rotaxane.

tetrabutylammonium fluoride (TBAF) to a $\mathrm{CD}_{3} \mathrm{CN}$ solution of $2-\mathrm{H}_{2} \cdot 4 \mathrm{PF}_{6}$, the ${ }^{1} \mathrm{H}$ NMR spectrum revealed an equal amount of a new translational isomer in addition to the original one, i.e., translational isomerization of the [2] rotaxane $2-\mathrm{H}_{2}{ }^{4+}$ (i) was slow under these conditions and (ii) required the exchange of all four of its counteranions. The addition of an additional 2 equiv of TBAF to this solution completely removed the signals of the original "stretched" isomer from the spectrum, resulting in the new translational isomer becoming the only species in solution (Figure 5). The significant downfield shift of the pyridinium protons suggests their possible $[\mathrm{C}-\mathrm{H} \cdots \mathrm{O}]$ hydrogen bonding with the oxygen atoms of the DB24C8-like units; the slight broadening of the aromatic signal $\left(\mathrm{H}_{\mathrm{Ar}}\right)$ and the complicated signals for the protons of the ethylene glycol units of the molecular cage component are consistent with extrusion of the $n$-octyl chain through one of the 34-membered-ring openings. Through 2D COSY and NOSY experiments, we identified most of the signals of this new translational isomer in the ${ }^{1} \mathrm{H}$ NMR spectrum in $\mathrm{CD}_{3} \mathrm{CN}$ at $298 \mathrm{~K}$. In this translational isomer, the methylene protons of the $n$-hexyl chain of the dumbbellshaped component are strongly shielded (see, for example, the signals of $\mathrm{H}_{3}$ and $\mathrm{H}_{4}$ ) by the aromatic units of molecular

(9) Kihara, N.; Tachibana, Y.; Kawasaki, H.; Takata, T. Chem. Lett. 2000, 506-507. 7004 


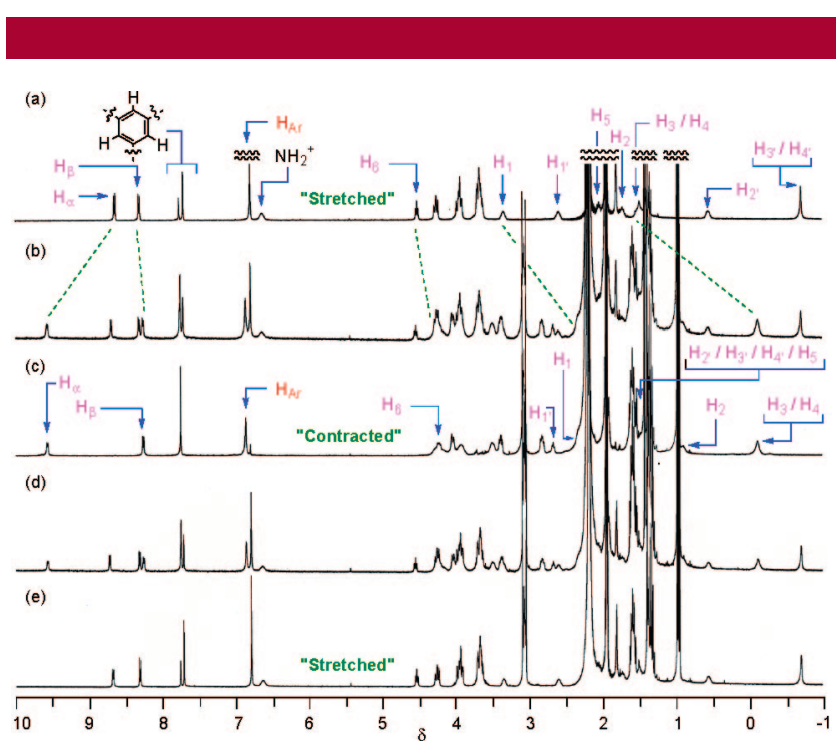

Figure 5. ${ }^{1} \mathrm{H}$ NMR spectra (400 MHz, $\mathrm{CD}_{3} \mathrm{CN}, 298 \mathrm{~K}$ ) of (a) the [2] rotaxane $2-\mathrm{H}_{2} \cdot 4 \mathrm{PF}_{6}$; (b) the mixture obtained after adding TBAF ( 2 equiv) to the solution in (a); (c) the mixture obtained after adding TBAF (2 equiv) to the solution in (b); (d) the mixture obtained after adding $\mathrm{Ca}\left(\mathrm{BF}_{4}\right)_{2}$ (1 equiv) to the solution in (c); and (e) the mixture obtained after adding $\mathrm{Ca}\left(\mathrm{BF}_{4}\right)_{2}$ (1 equiv) to the solution in (d).

cage $\mathbf{1}$, whereas those of the $n$-octyl group (see, for example, $\mathrm{H}_{3^{\prime}}$ and $\mathrm{H}_{4^{\prime}}$ ) are dramatically less shielded (Figure 5c). In addition, the presence of a cross peak between the signals of the methylene protons adjacent to the pyridinium group and the aromatic protons of the molecular cage component in the 2D NOSY spectrum supports the "contracted" nature of this translational isomer.

We believe that the main driving force leading to this unique "contracted" form is the fluoride anions" disruption of $\left[\mathrm{N}^{+}-\mathrm{H} \cdots \mathrm{O}\right]$ hydrogen bonding between the $\mathrm{NH}_{2}{ }^{+}$centers and the DB24C8-like units of molecular cage 1 being relatively stronger than that of the $[\mathrm{C}-\mathrm{H} \cdots \cdot \mathrm{O}]$ hydrogen bonding of the pyridinium ions. Subsequent addition of 2 equiv of $\mathrm{CaBF}_{4}$, to remove the fluoride anions from solution through precipitation of $\mathrm{CaF}_{2}$, provided a spectrum (Figure 5e) similar to that of the original [2] rotaxane $2-\mathrm{H}_{2} \cdot 4 \mathrm{PF}_{6}$ in the same solvent (Figure 5a), i.e., the stretched form of $2-\mathrm{H}_{2}{ }^{4+}$ was regenerated. Thus, the contracted and elongated forms of the [2] rotaxane $2-\mathrm{H}_{2}{ }^{4+}$ can be generated reversibly in $\mathrm{CD}_{3} \mathrm{CN}$ through counteranion exchange $\left(\mathrm{F}^{-}\right.$vs $\mathrm{PF}_{6}{ }^{-}$/ $\mathrm{BF}_{4}^{-}$), providing a simple system for mimicking the function of skeletal muscles. The addition of $\mathrm{Cl}^{-}, \mathrm{Br}^{-}$, or $\mathrm{I}^{-}$ions (as tetrabutylammonium salts) to a $\mathrm{CD}_{3} \mathrm{CN}$ solution of the [2] rotaxane $2-\mathrm{H}_{2} \cdot 4 \mathrm{PF}_{6}$ failed to contract the molecular muscle; thus, the operation of the molecular muscle is selectively controlled by the formation of the tight binding $\mathrm{NH}_{2}^{+} / \mathrm{F}^{-}$ion pair.

To estimate the percentage change in the length of the thread-like component between the contracted and stretched states of the [2] rotaxane $2-\mathrm{H}_{2}{ }^{4+}$, we performed molecular dynamics (MD) simulations in continuums of $\mathrm{CHCl}_{3}$ and water and in the gas phase (see Supporting Information). When starting the MD simulation from the solid state structure of the [2] rotaxane $2-\mathrm{H}_{2}{ }^{4+}$, in which both pyridinium units are stacked with the aromatic component of the molecular cage, the molecular conformation of $2-\mathrm{H}_{2}{ }^{4+}$ changed into the stretched form during the equilibration step under all solvent models. This result suggests that the stacking structure was not the predominant coconformation of the [2] rotaxane $2-\mathrm{H}_{2}{ }^{4+}$ in solution. Using the aromatic carbon atoms located between the two tert-butyl groups as reference points, our MD simulations revealed that the average lengths of the thread in the stretched and contracted states were 39.7 and $25.3 \AA$, respectively. Thus, the percentage change in molecular length is about $36 \%$ between the two states, which is larger than the percentage change $(\sim 27 \%)$ in human muscle. ${ }^{2 a}$ Figure 6 provides the lowest-

a)

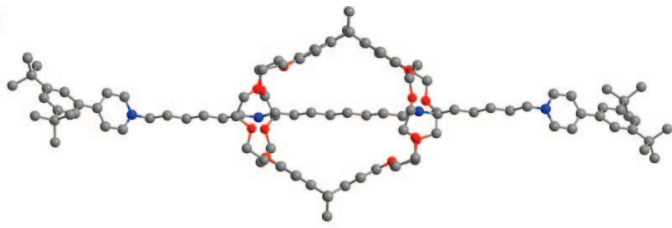

b)

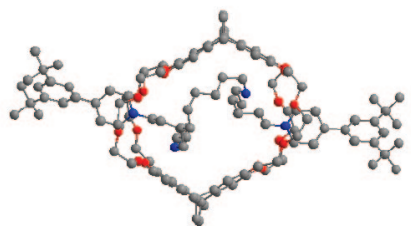

Figure 6. Lowest-energy structures of $2-\mathrm{H}_{2}{ }^{4+}$ obtained from MD simulations of the (a) stretched and (b) contracted forms. Atom labels: $\mathrm{C}$, gray; $\mathrm{O}$, red; $\mathrm{N}$, blue.

energy structures of $2-\mathrm{H}_{2}{ }^{4+}$ in the two different states obtained from simulations in the continuum water model.

We have prepared a molecular cage-based [2] rotaxane that functions as an artificial molecular muscle that is controlled through the addition and removal of fluoride anions. The unique container-like structure of molecular cage $\mathbf{1}$ compared to common macrocycles provides an alternative possibility in the design of molecular muscles. We are at present investigating the further use of container-like host molecules within other functional molecules.

Acknowledgment. We thank the National Science Council (Taiwan) for financial support (NSC-95-2113-M-002-016MY3) and the National Center for High-performance Computing for computational resources.

Supporting Information Available: Synthetic procedures and characterization data for the [2] rotaxane $2-\mathrm{H}_{2} \cdot 4 \mathrm{PF}_{6}$. This material is available free of charge via the Internet at http://pubs.acs.org.

OL802648H 